\title{
Cost of reproduction in Fucus distichus
}

\author{
P. O. Ang, Jr* \\ Department of Botany, University of British Columbia, Vancouver, British Columbia, Canada V6T 1Z4
}

\begin{abstract}
Reproductive effort (ratio of fertile to total plant dry weight) was measured in Fucus distichus L. emend. Powell. On average, $12.7 \%$ of plant dry weight is in reproductive biomass and this amount is relatively constant over most months. Reproductive effort does not vary among plants of different sizes and dry weights. However, fertile plants are significantly $(p<0.05)$ bigger than the nonfertile plants, and have a better survival rate. There is no clear indication of cost of reproduction with respect to the longevity of fertile vs non-fertile plants. Fertile plants, especially those $>17 \mathrm{~cm}$ in length, tend to exhibit negative or zero growth much more often than non-fertile plants, suggesting that the cost of reproduction may be manifested in the form of reduced growth, rather than in greater mortality or shorter longevity of the fertile plants. The failure to detect cost of reproduction with respect to mortality and longevity may be due to the modular nature of the plants, where cost occurs at the level of the modules (branches) rather than at the level of the whole plant.
\end{abstract}

\section{INTRODUCTION}

Reproductive effort is the amount of resources allocated to reproduction over a defined period of time (Begon et al. 1990). This is one of the central concepts in life history theory. There is, however, an unresolved controversy as to how this effort can be measured, especially in plants (Harper \& Ogden 1970, Abrahamson \& Gadgil 1973, Harper 1977, Bell 1980, Thompson \& Steward 1981, Abrahamson \& Caswell 1982, Bazzaz \& Reekie 1985, Goldman \& Willson 1986, Reekie \& Bazzaz 1987a, b, c, Chapin 1989). Conventionally, reproductive effort is expressed as the ratio of the dry weight of reproductive biomass to that of the whole plant, although the question of what constitutes the reproductive biomass remains debatable (see Bazzaz \& Reekie 1985 for discussion). Bell (1980) argued that any measurement of reproductive effort could be of evolutionary significance only if it is translated into units of fitness. He further argued that the concept of the cost of reproduction is more relevant to the life history theory when it is defined as the effect of a given quantity of present reproduction on the expectation of future survival, than when it is defined in terms of resource allocation. What is important is not how much

\footnotetext{
- Present address: Fisheries Research Laboratory, PO Box 550 , Halifax, Nova Scotia, Canada B3J 2S7
}

of the resource(s) or energy is allocated to reproductive or non-reproductive structures, but how reproduction could reduce the future chance of survival of the adult (survival cost), and/or future reproduction (fecundity cost) (Bell \& Koufopanou 1986).

The question on the cost of reproduction in algae has only been addressed in a few studies (e.g. Klinger 1988, Pfister 1990). Many phenological observations have indicated a close link between increase in length and reproduction, where rapid elongation is concurrent with or followed by the onset of reproduction (see review by De Wreede \& Klinger 1988). In many cases, the blades or erect thalli become necrotic and die back after the discharge of reproductive propagules like gametes or spores (e.g. Kain 1975, Ang 1985). This seems to suggest a survival cost associated with reproduction. However, exceptions have also been observed in which vegetative blades decayed without the formation of any reproductive structures (e.g. Klein 1987). In addition, reproduction might occur just prior to the time of natural die back of the plants as a response to changing environmental conditions. Thus, reproduction itself is not the cause of such die back.

Bell \& Koufopanou (1986) stated 2 basic ways by which the cost of reproduction can be measured: by analysis of causality by experiments and by analysis of correlation by observations. Inherent with the difficulties in manipulating reproduction in algae, e.g. 
experimentally reducing reproductive output from a thallus, the first approach has not been attempted nor is there currently a feasible way to do it. The second approach is simpler, though it is not without its limitations. Correlation between components of fitness, say reproductive output and mortality, may be significant but may be spurious due to covariation with a third factor. Nevertheless, observation of the pattern in the natural populations, i.e. phenotypic correlation, may provide some basic information that can point to the direction of future research on the topic of cost of reproduction in algae.

In this paper, reproductive effort of individual plants of Fucus distichus L. emend. Powell is given as a ratio between the dry weight of the receptacles and that of the whole plant. Several hypotheses on the cost of reproduction (sensu Bell 1980) are tested based on monitoring the fate of fertile and non-fertile plants within the population. If reproduction has a significant survivai cost, then one or all of the following phenomena should be observed: the mortality rate of fertile plants should be higher than that of non-fertile plants, fertile plants should have a shorter longevity (months to live) and should experience slower growth than the non-fertile plant.

It is not possible to evaluate directly and independently the fecundity cost of reproduction. Egg production (reproductive output) has been shown to be correlated with plant size (length) (Ang 1991a). Fecundity cost is therefore inferred from the effect of reproduction on changes in plant size, hence presumably also on reproductive output.

Reproduction is both age- and size-dependent in Fucus distichus (Ang 1991a), but size is a better descriptor of reproductive events, and of growth and mortality, than is age (Ang 1991a, b). The cost of reproduction is therefore evaluated only with respect to the size of the individuals.

\section{MATERIALS AND METHODS}

Fucus distichus plants form a distinct intertidal zone on the seawall along False Creek, Vancouver, British Columbia, Canada. Fertile plants are found in the population throughout the year but peak reproductive season is in the fall and winter. Plants generally grow faster during spring and summer. Plant growth is apical and branching is dichotomous. Reproductive structures (conceptacles) develop from cells in the swollen tips (receptacles) of higher order branches. Plant mortality is size-dependent with larger plants experiencing higher mortality during summer. Ang (1991a, b) gave a more detailed description of the study area and the general ecology of the population.
Between 4 and 7 quadrats $(10 \times 10 \mathrm{~cm})$ were randomly placed in the Fucus distichus bed each month from October 1985 to November 1987 (except November 1986). All plants within the quadrats were collected and brought back to the laboratory. Sizes of the plants were measured to the closest $\mathrm{mm}$ as length from the base of the holdfast to the tip of the longest branch. Each plant was then blotted dry on a paper towel and wet weight was measured on a Mettler PB300 top loading balance. Each plant was placed in an oven at $105^{\circ} \mathrm{C}$ for $6 \mathrm{~h}$ (Brinkhuis 1985) and then weighed again to obtain its dry weight. For fertile plants, the receptacles were excised and dried separately from the remaining vegetative part. The dry weight of fertile parts is expressed as a proportion of the total dry weight and is referred to as the reproductive effort. Dry weight data were $\log (x+1)$ transformed and the proportion data were arcsin squareroot $(x+3 / 8)$ transformed (Chap. 14 in Zar 1984) to meet the assumptions of normality (Lilliefor's Test) and homogeneity of the variances (Bartlett's Test) of parametric statistics. Linear regression lines were fitted to describe the relationship between plant size and plant dry weight, dry weight of receptacles and plant size and total plant dry weight for each month. Pooling of monthly data was attempted by testing for the homogeneity of slopes of the regression lines using the following model of analysis of variance (ANOVA) (Kleinbaum \& Kupper 1978, Wilkinson 1988):

$$
Y=\text { constant }+ \text { Treatment }+X+\text { Treatment } \times X
$$

where $Y$ is the dependent variable, e.g. plant dry weight; Treatment is time (mo); and $X$ is the independent variable (or covariate), e.g. plant size. Pooling of data is justified if the interaction between the treatment and the covariate is not significant $\left(p_{\text {Treatment } x} x>0.05\right)$.

Cost of reproduction was measured in terms of the probability of mortality due to reproduction, and the effect of reproduction on longevity (i.e. number of months a plant survived after becoming reproductive) and growth rate. Three $0.25 \mathrm{~m}^{2}$ permanent quadrats were set up in the Fucus distichus bed and plants within each quadrat were mapped and monitored monthly. Only plants $\geq 4.5 \mathrm{~cm}$ in length were considered because plants $<4.5 \mathrm{~cm}$ never became reproductive (Ang 1991a). Information gathered inclucled the plants' reproductive status; whether they survived in the following month of sampling (mortality); if they survived, how long (mo) did they live before they eventually died or disappeared from the quadrat (longevity); and changes in plant length between samplings (growth rate). Monthly data used were those that roughly represented the 4 seasons of the year: fall (October 1985), winter (January 1986 and 
1987), spring (May 1986 and April 1987), and summer (August 1986). These data also represented different plants sampled in each of these months. Different data transformations (Chap. 14 in Zar 1984) were attempted but were not successful in achieving normality and homogeneity of variances in the data, so distributionfree contingency table analysis was used to assess the relationship between reproduction, mortality, longevity and growth rate. To improve the sample size for chisquare analysis, pooling of data was attempted. Heterogeneity chi-square tests were carried out among contingency tables from different time periods. If the results of the chi-square tests were not significant ( $p>0.05$ ), then monthly data were pooled and analyzed in a single contingency table (Zar 1984). The effect of plant size on the relationship between reproduction and other demographic events was assessed using $\log$ linear analysis in a 3-way contingency table (see Caswell 1989 for more details of this method and other examples of its application). The G-statistic was employed in all contingency table analyses and log linear analyses (Sokal \& Rohlf 1981).

Fertile plants may remain reproductive for a number of months after the initial formation of receptacle(s), or the plant may become vegetative after the decay or loss of the receptacle. To further evaluate the effect of reproduction on longevity, the number of months a plant remained reproductive, given as a ratio over the number of months a plant survived after first becoming reproductive (longevity), was regressed against longevity of the fertile plant. No data transformation was necessary to achieve normality and homogeneity of variances in this ratio. Pooling of data from different time periods was attempted based on test of homogeneity of regression slopes using the model of ANOVA described above. All statistical analyses were performed using SYSTAT (Wilkinson 1988).

\section{RESULTS}

Considering only the fertile plants, the relationship between log transformed plant dry weight and plant size is not significantly different over time (ANOVA; $\left.F_{24,245}=1.19, \mathrm{p}=0.256, \mathrm{n}=295\right)$. The data representing monthly samples from October 1985 to November 1987 (except November 1986) can therefore be pooled. Based on these pooled data, the linear relationship between log transformed plant dry weight and plant size is positive and significant (Fig. 1).

The relationship between log transformed receptacle dry weight and plant size, as well as that between receptacle dry weight and plant dry weight, were significantly different over time (ANOVA; $p>0.05$ ). This is due to the presence of a non-significant relationship

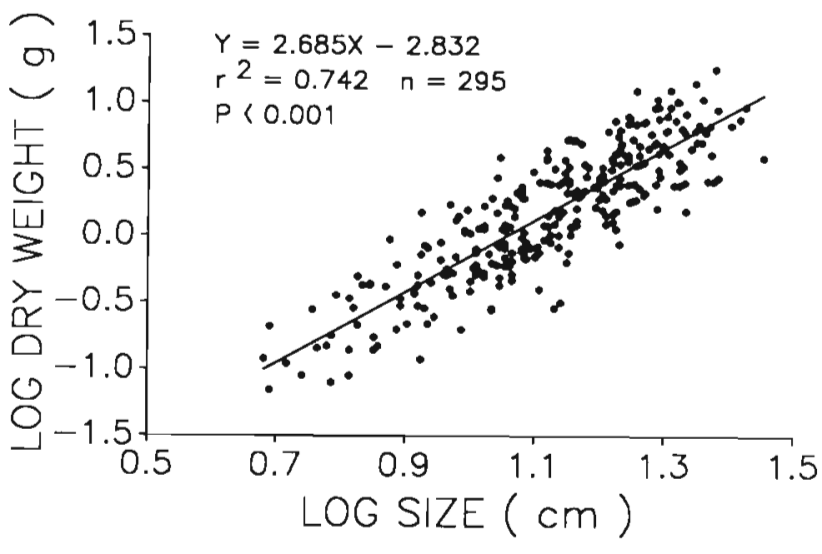

Fig. 1 Fucus distichus. Linear regression of plant dry weight vs plant size. Only fertile plants $(\geq 4.5 \mathrm{~cm})$ were included

(linear regression; $p>0.05$ ) between these parameters in those monthly data from fall to early winter (November to December 1985, September to November 1987) and from late spring to summer (May to August 1986, April to August 1987). Monthly data from fall to early winter of 1986 (September, October and December 1986), and from winter to mid-spring (January to April 1986, 1987), all showed a significant relationship between these parameters (linear regression; $\mathrm{p}<0.05$ ). While these monthly data can be pooled (ANOVA; $p>0.05$ ) to show a single regression line between these parameters (Fig. 2A, B), similar relationships can also be demonstrated if all monthly data from October 1985 to November 1987 (except November 1986) were pooled. The 2 regression lines, one including only monthly data which showed significant relationship between these parameters and the other including all monthly data, are not significantly different from each other (ANOVA; $p>0.05$ ).

The relationship between arcsin square-root transformed reproductive effort and log transformed plant size and plant dry weight is significantly different over time (ANOVA $;$ p <0.05). With a few exceptions, most monthly data showed a slope of the linear regression line that is not significantly different from 0 (ANOVA; $p>0.05$ ). For both the relationship between reproductive effort and plant size, and that between reproductive effort and plant dry weight, pooling these monthly data resulted in a regression line that is negative and significant $(p<0.05)$, but only $<4 \%$ of the variation within the data could be accounted for by the pooled regression line (Fig. $3 \mathrm{~A}, \mathrm{~B}$ ). The slope of this regression line is not significantly different (ANOVA; $p>0.05$ ) from that of the regression line that resulted from considering all monthly data, including those few exceptions that showed a significant linear regression between reproductive effort and plant size (April and June 1987), and between reproductive effort and plant dry weight 


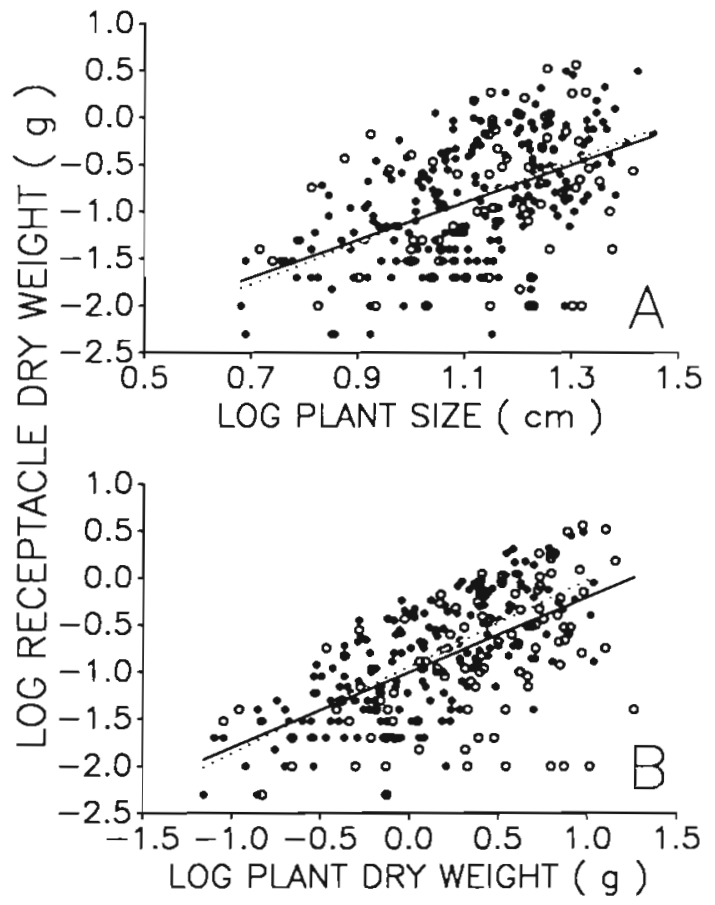

Fig. 2. Fucus distichus. Linear regressions of receptacle dry weight vs (A) plant size and (B) plant dry weight. (-) Regression for monthly data with significant linear relationship between parameters; $(\cdots \cdot)$ regression for all monthly data; (-) data points from monthly data with significant linear relationship; (o) data points from data with non-significant linear relationship between parameters. (A) Significantly related data (一): $Y=-3.3+2.186 X, \mathrm{r}^{2}=0.328, \mathrm{n}=222, \mathrm{p}<0.001$; all data (…): $Y=-3.1+1.999 X, r^{2}=0.245, n=295, p<0.001$. (B) Sig. nificantly related data $(-): Y=-0.97+0.917 X, \mathrm{r}^{2}=0.507$, $\mathrm{n}=237, \mathrm{p}<0.001$ all data $(\cdots \cdots): Y=-1.0+0.802 X, \mathrm{r}^{2}=0.384$, $\mathrm{n}=295, \mathrm{p}<0.001$

(October 1985, January and September 1986, April and June 1987). This means that the proportion of plant dry weight allocated to reproduction (receptacle) cannot be predicted based on plant size or plant dry weight alone. On average, about $12.7 \% \pm 0.01 \%$ SE of the plant dry weight is allocated to receptacles.

A contingency table of reproduction vs mortality (Table 1) suggests that there is a greater chance of mortality for non-fertile plants than for fertile plants. Longevity was first grouped into 3 categories to minimize the presence of sparse cells in the contingency table. These categories are: survival for 1 to 2 mo, 3 to $4 \mathrm{mo}$, or $>4 \mathrm{mo}$. Based on the pooled data (Table 2), fertile plants had about equal chances of surviving in each longevity category, but non-fertile plants either survived only for 1 to 2 mo or $>4$ mo but more rarely between 3 to $4 \mathrm{mo}$. To further test this relationship, the actual number of months a plant survived was used in the analysis. The results (Table 3 ) indicate that $53 \%$ of the non-fertile plants survived for 1 to $3 \mathrm{mo}$. Propor-

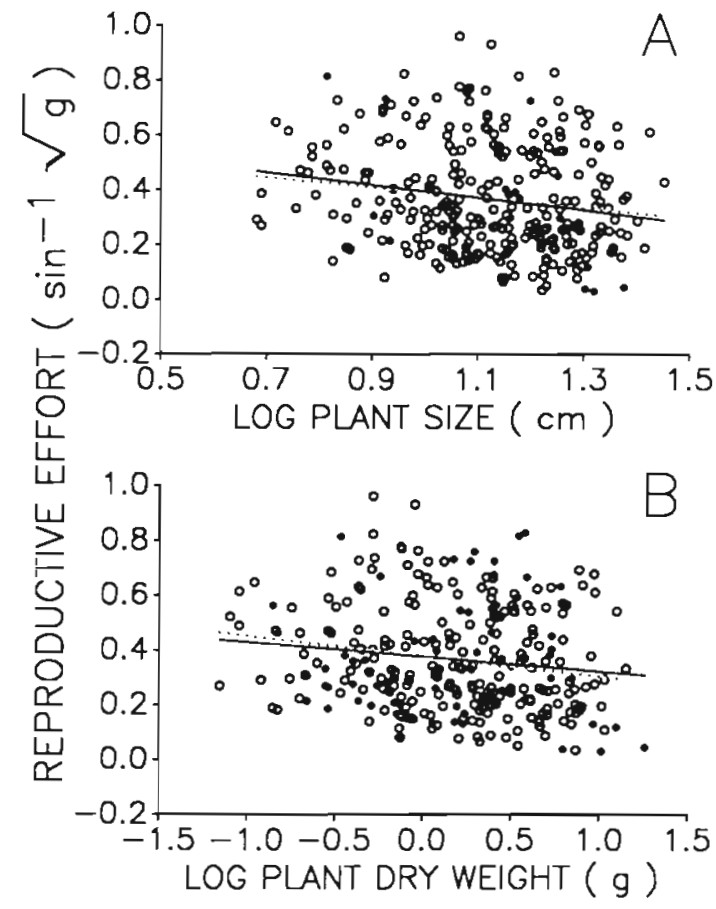

Fig. 3. Fucus distichus. Linear regressions of reproductive effort vs (A) plant size and (B) plant dry weight. (-) Regression for monthly data with non-significant linear relationship between parameters; (...) regression for all monthly data. Other symbols as in Fig. 2. (A) Pooled non-significantly related data $(-): Y=0.578-0.187 X, \mathrm{r}^{2}=0.024, \mathrm{n}=277, \mathrm{p}=$ 0.010 ; all data $(\cdots \cdots): Y=0.625-0.23 X, \mathrm{r}^{2}=0.035, \mathrm{n}=295, \mathrm{p}=$ 0.001 (B) Pooled non-significantly related data $(-): Y=$ $0.380-0.074 X, \mathrm{r}^{2}=0.037, \mathrm{n}=224, \mathrm{p}=0.004$; all data $(\cdots \cdots): Y$ $=0.377-0.053 X, r^{2}=0.018, n=295, p=0.020$

tionally, a greater number of them also survived more than 7 mo, compared to the fertile plants. Most fertile plants $(88 \%)$ survived from 1 to 6 mo. As a general trend, there is no real difference between the fertile and non-fertile plants; most of them $(52 \%)$ survived for 1 to 3 mo. The number surviving beyond 3 mo diminished nearly monotonically.

Table 1. Fucus distichus. Contingency table of the relationship between reproduction and mortality based on pooled data from October 1985, January, May 1986, January, April 1987. Row percentage given in parentheses

\begin{tabular}{|c|c|c|c|}
\hline \multirow[t]{2}{*}{ Reproduction } & \multicolumn{2}{|c|}{ Mortality } & \multirow[t]{2}{*}{ Total } \\
\hline & Died & Survived & \\
\hline Non-fertile & $45(10.2 \%)$ & $399(89.8 \%)$ & $444(100 \%)$ \\
\hline Fertile & $9(5.2 \%)$ & $164(94.8 \%)$ & $173(100 \%)$ \\
\hline Total & $54(8.8 \%)$ & $563(91.3 \%)$ & $617(100 \%)$ \\
\hline \multicolumn{4}{|c|}{$\begin{array}{l}G \text {-test: } G=8.342 ; \mathrm{df}=1, \mathrm{p}<0.001 \\
\text { Heterogeneity test for pooled data: } \chi^{2}=1.527 ; \mathrm{df}=4 \\
\qquad \mathrm{p}=0.822\end{array}$} \\
\hline
\end{tabular}


Table 2. Fucus distichus. Contingency table of the relationship between reproduction and longevity based on pooled data from October 1985, January, May, August 1986, January, and April 1987. Column percentage given in parentheses

\begin{tabular}{|c|c|c|c|}
\hline \multirow{2}{*}{$\begin{array}{l}\text { Longevity } \\
\text { (mo) }\end{array}$} & \multicolumn{2}{|c|}{ Reproduction } & \multirow[t]{2}{*}{ Total } \\
\hline & Non-fertile & Fertile & \\
\hline $1-2$ & $194(41.5 \%)$ & $51(32.3 \%)$ & $245(39.1 \%)$ \\
\hline $3-4$ & $98(20.9 \%)$ & $53(33.5 \%)$ & $151(24.1 \%)$ \\
\hline$>4$ & $176(37.6 \%)$ & $54(34.2 \%)$ & $230(36.7 \%)$ \\
\hline Total & $468(100 \%)$ & $158(100 \%)$ & $626(100 \%)$ \\
\hline \multicolumn{4}{|c|}{$\begin{array}{l}G \text {-test: } G=20.538 ; \mathrm{df}=2, p<0.001 \\
\text { Heterogeneity test for pooled data: } \chi^{2}=10.449 ; \mathrm{df}=10 \\
\qquad \mathrm{p}=0.402\end{array}$} \\
\hline
\end{tabular}

For the reproduction vs growth rate contingency table, growth rate was also grouped into 3 categories: negative to 0 growth, $>0$ to $2 \mathrm{~cm} \mathrm{mo}^{-1}$ and $>2 \mathrm{~cm} \mathrm{mo}^{-1}$. As indicated by pooled data (Table 4), most fertile plants $(52 \%)$ exhibited negative or no growth, and most non-fertile plants $(50.3 \%)$ exhibited positive growth of $<2 \mathrm{~cm} \mathrm{mo}^{-1}$. Proportionally, there were also more non-fertile than fertile plants that exhibited growth $>2 \mathrm{~cm} \mathrm{mo}^{-1}$.

The potential influence of plant size on the patterns observed above was assessed by log linear analyses on 3-way contingency tables that include plant size (Table 5). Data on plant sizes were first plotted in a scatter diagram. Based on the best grouping that will allow equal number of plants for each group, plant sizes were divided into 3 classes: 4.5 to $11 \mathrm{~cm},>11$ to $17 \mathrm{~cm}$, and $>17 \mathrm{~cm}$. The interaction among reproduction, size and mortality is not significant (Table 5A). Chances of mortality were not significantly different among size

Table 3. Fucus distichus. Contingency table of the relationship between reproduction and longevity based on pooled data from different time periods as given in Table 2. Column percentage given in parentheses

\begin{tabular}{|crrrr|}
\hline $\begin{array}{c}\text { Longevity } \\
\text { (mo) }\end{array}$ & \multicolumn{2}{c}{ Reproduction } & Total \\
\hline 1 & $92(19.7 \%)$ & $26(16.5 \%)$ & $118(18.9 \%)$ \\
2 & $102(21.8 \%)$ & $25(15.8 \%)$ & $127(20.3 \%)$ \\
3 & $53(11.3 \%)$ & $26(16.5 \%)$ & $79(12.6 \%)$ \\
4 & $45(9.6 \%)$ & $27(17.1 \%)$ & $72(11.5 \%)$ \\
5 & $56(12.0 \%)$ & $13(8.2 \%)$ & $69(11.0 \%)$ \\
6 & $34(7.3 \%)$ & $22(13.9 \%)$ & $56(9.0 \%)$ \\
7 & $25(5.3 \%)$ & $10(6.3 \%)$ & $35(5.6 \%)$ \\
8 & $17(3.6 \%)$ & $2(1.3 \%)$ & $19(3.0 \%)$ \\
9 & $22(4.7 \%)$ & $4(2.5 \%)$ & $26(4.2 \%)$ \\
$>9$ & $22(4.7 \%)$ & $3(1.9 \%)$ & $25(4.0 \%)$ \\
Total & $468(100 \%)$ & $158(100 \%)$ & $626(100 \%)$ \\
G-test: $G=48.722 ; \mathrm{df}=9, \mathrm{p}<0.001$ & \\
\hline
\end{tabular}

Table 4. Fucus distichus. Contingency table of the relationship between reproduction and growth rate $\left(\mathrm{cm} \mathrm{mo}^{-1}\right)$ based on pooled data from different time periods as given in Table 2. Column percentage given in parentheses

\begin{tabular}{|c|c|c|c|}
\hline \multirow[t]{2}{*}{ Growth rate } & \multicolumn{2}{|c|}{ Reproduction } & \multirow[t]{2}{*}{ Total } \\
\hline & Non-fertile & Fertile & \\
\hline$\leq 0$ & $142(30.3 \%)$ & $90(52.0 \%)$ & $232(36.1 \%)$ \\
\hline$>0$ to 2 & $236(50.3 \%)$ & $66(38.2 \%)$ & $302(47.0 \%)$ \\
\hline$>2$ & $91(19.4 \%)$ & $17(9.8 \%)$ & $108(16.8 \%)$ \\
\hline Total & $469(100 \%)$ & $173(100 \%)$ & $642(100 \%)$ \\
\hline \multicolumn{4}{|c|}{$\begin{array}{l}G \text {-test: } G=54.384 ; \mathrm{df}=2, \mathrm{p}<0.001 \\
\text { Heterogeneity test for pooled data: } \chi^{2}=9.18 ; \mathrm{df}=15 \\
\qquad \mathrm{p}=0.868\end{array}$} \\
\hline
\end{tabular}

classes, irrespective of whether plants were fertile or not. But within each size class, fertile plants had a better chance of surviving than the non-fertile plants. Proportionally, more fertile plants were in the larger size classes. Interaction among reproduction, size, and longevity is also not significant (Table $5 \mathrm{~B}$ ). The pattern of longevity appears to be consistent among non-fertile plants of different size classes; in each case a greater number of plants survived either for 1 to 2 mo or $>4 \mathrm{mo}$, but more rarely for 3 to $4 \mathrm{mo}$. Fertile plants of the smallest size class survived relatively longer, whereas longevity was about the same among those in the larger size classes. The interaction among reproduction, size, and growth rate is significant (Table 5C), suggesting that differences in growth rates were not only dependent on the reproductive status of the plants, but also on their sizes. The pattern observed earlier between reproduction and growth rate (Table 4) is consistent with that of plants in the first size class. However, plants in the second and third size classes showed a less consistent pattern. Both nonfertile and fertile plants in the second size class exhibited a greater chance of positive growth, whereas only fertile plants $>17 \mathrm{~cm}$ exhibited a greater chance of negative growth. Fertile plants $>17 \mathrm{~cm}$ were far more likely $(69.9 \%)$ to exhibit negative growth than were non-fertile plants of the same size class $(50 \%)$.

There is no significant difference in the relationship between the fertility/longevity ratio and plant longevity over time (ANOVA; $F_{4.49}=1.111, \mathrm{p}=0.362, \mathrm{n}=59$ ), as well as between this ratio and plant size at different times (ANOVA; $F_{4,49}=0.622, \mathrm{p}=0.649, \mathrm{n}=59$ ). Both relationships are non-significant (linear regression; $\mathrm{df}=1,57, \mathrm{p}>0.05, \mathrm{n}=59$ ). The mean ratio is not different among times $\left(\right.$ ANOVA $_{i} F_{4,54}=0.804, \mathrm{p}=0.528$, $\mathrm{n}=59$ ). On average, from the time a plant first became fertile, it would remain fertile $65.7 \%$ ( $\pm 4.4 \% \mathrm{SE}$ ) of the time before it died. The longest time a plant remained fertile was 10 mo. 
Table 5. Fucus distichus. Contingency tables and results of log linear analyses of the relationship among reproduction, size and (A) mortality, (B) longevity and (C) growth rate. Row percentage in parentheses

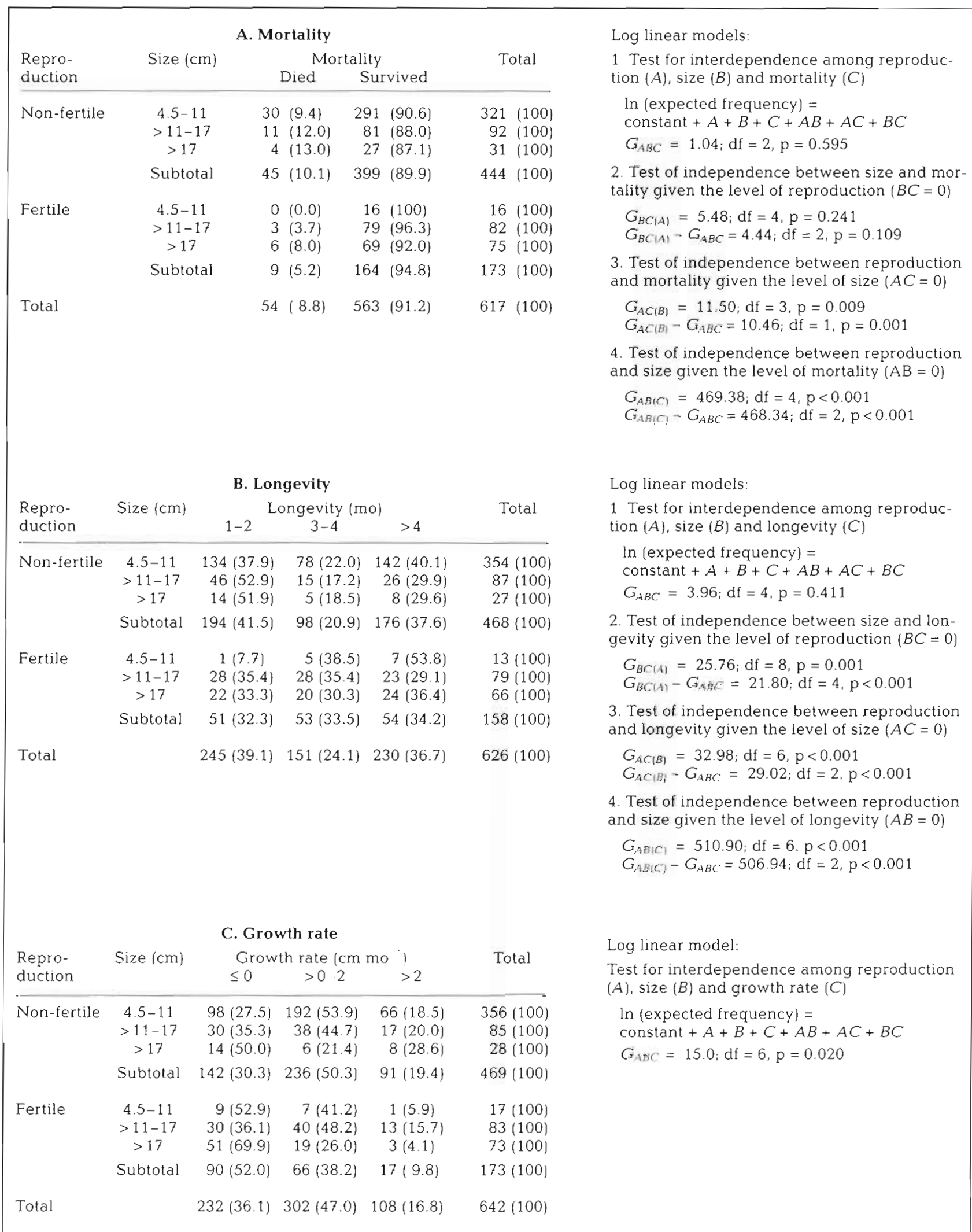




\section{DISCUSSION}

The large scatter of data in Fig. 2A, B, showing respectively the relationship between the receptacle dry weight and plant size, and between receptacle and plant dry weights, may be a result of the presence of receptacles either at early stages of development or in the process of attrition, on different branches of the plant and/or on plants of different sizes. The former is particularly true for those monthly data from fall to early winter when the reproductive season of the population is reaching its peak. The latter will be true for those data from late spring to summer when the proportion of reproductive plants in the population is at its lowest. During winter and spring, more plants would have more fully developed receptacles. However, there is still significant variation in the sizes of receptacles among plants such that a linear regression can only explain $<51 \%$ of the variation within the data. A polynomial regression did not significantly improve the amount of variation explained.

No such apparent seasonal pattern was observed with respect to reproductive effort in the population of Fucus distichus from False Creek. Reproductive effort appears to be independent of plant size and total plant dry weight over time. It remains to be seen if this pattern holds for other $F$. distichus, or other algal, populations. The allocation of a relatively constant proportion of resource to different parts of the algal thallus, regardless of their size, has been reported for Durvillaea antarctica (Chamisso in Choris) Hariot (Lawrence 1986) and Postelsia palmaeformis Ruprecht (Lawrence \& McClintock 1988). However, none of these authors reported allocation specifically to reproductive parts. More recently, Ảberg (1990) found reproductive effort to increase with plant size in a population of Ascophyllum nodosum (L.) Le Jolis.

The mean allocation of only $12.7 \%$ of its total dry weight biomass to reproduction in Fucus distichus is relatively small. There is considerable variability in the amount of this allocation, with some individuals within the population allocating as high as $67 \%$ of their total dry weight biomass to reproduction. F. distichus plants from False Creek do not become reproductive when $<4.5 \mathrm{~cm}$ in size (Ang 1991a). Given a minimum size for reproduction and a linear relationship between reproductive and vegetative weights, the relationship between percent reproductive allocation (i.e. reproductive effort) and total or vegetative weight will be a decreasing slope approaching a constant percent reproductive allocation (Weiner 1988, Åberg 1990). This however, is not demonstrated in the present study. This is mainly because of the large variation in the reproductive effort of the plants sampled.
Early works (e.g. Baardseth 1970) measured the proportion of reproductive biomass over biomass of the whole plant without referring to the concept of reproductive effort. Vernet \& Harper (1980) were probably the first to introduce the idea in the algal literature. In their attempt to find some answers to the evolutionary question on the cost of sex in algae, they estimated that the eggs of various species of Fucus constituted only about 0.1 to $0.4 \%$ of the total plant weight. Ford et al. (1983) and Edyvean \& Ford (1984) found up to $25 \%$ by volume of yearly growth in asexual thalli and $55 \%$ in sexual thalli of the coralline red alga Lithophyllum incrustans Phil. to be made up of conceptacles. Klinger (1984) reported mean sorus surface area to be 13.2 to $31.7 \%$ of the total blade area in Laminaria ephemera Setchell, and 1.28 to $30.48 \%$ in $L$. setchellii Silva. The ratios varied with time and locality. Novaczek (1984), using an estimated $5 \mathrm{mg} \mathrm{cm}^{-2}$ as the dry weight of sporangia and accessory structures, calculated that fertile tissue constituted about $20 \%$ of the yearly tissue production in Ecklonia radiata (C. Ag.) J. Ag. at shallow depth (7 m), and $10 \%$ of the production at $15 \mathrm{~m}$. Schiel (1985) argued that for Sargassum spp. and Cystoseira spp., reproductive structures developed along the entire length of the annual growth which is about 80 to $90 \%$ of the plant biomass. The true cost of reproduction must take into account this whole vegetative structure that supports the fertile material. Cousens (1986) made a distinction between reproductive effort and reproductive proportion in Ascophyllum nodosum, the former being a ratio of weight of receptacle over the quantity of net annual production, and the latter a ratio of weight of receptacle over total standing crop. He estimated reproductive dry weight biomass in $A$. nodosum to be 41.4 to $70.4 \%$ of the annual growth or 10 to $29 \%$ of the total standing crop. He also found reproductive effort to differ along exposure gradients, but not along vertical or latitudinal distribution in Nova Scotia, Canada. It is interesting to note that while there are only a few studies on algal reproductive effort, each study measured reproductive effort in a different way, making comparisons difficult. This is partly because of the very different morphology and phenology of the plants studied.

Although individuals of Fucus distichus can live longer than $1 \mathrm{yr}$, reproduction involves different receptacles in different branches. New receptacles continue to form while the old ones are dying or decaying, giving the impression of continuous reproduction at the level of the whole plant. This continuity is interrupted only if the formation of new receptacles does not catch up with the decay of the old ones, thus giving an impression of iteroparity. A branch inevitably dies after the decay of the receptacle (author's 
pers. abs.). Each branch may thus be considered as semelparous in its reproduction, though the eggs may not all be discharged simultaneously. Once a receptacle develops, it eventually occupies more than half the length of the branch. If each branch is considered separately as a module, the reproductive effort of each module would likely be much higher than that of the whole plant.

The modular character of the Fucus distichus plant also implies that there could be 2 levels of mortality: mortality of the modules (branches) vs that of the whole plant. Each module may die after becoming reproductive, but the entire plant may continue to survive if at least 1 terminal branch remains vegetative. This phenomenon is not infrequent in this $F$. distichus population and it has also been observed by Knight \& Parke (1950) for $F$. vesiculosus $L$. and $F$. serratus L. However, Edelstein \& McLachlan (1975) observed that in $F$. distichus ssp. distichus, new branches can still develop even if all terminal branches have become fertile.

The failure to detect a significantly greater probability of mortality in fertile than in non-fertile plants may be related to the modular character of the plants. Mortality of the modules may not be associated with that of the whole plant. Even if all the terminal branches become fertile, it will take a few months before the natural attrition of the terminal branches is complete, hence before the whole plant will eventually die. During this period when the terminal branches are being eroded, any mortality of the whole plant may be due to factors unrelated to reproduction. These factors could equally affect the mortality of non-fertile plants, as well as those fertile plants with vegetative branches. Although fertile plants are generally bigger than nonfertile plants (Table 5), the non-significant effect of size on mortality, given the level of reproduction, suggests that size is not one of these factors affecting plant mortality.

Other things being equal, the lack of interaction among reproduction, longevity and size suggests the absence of any cost of reproduction on longevity. The negative effect of reproduction and size on growth is easier to discern. Large proportions of fertile plants, especially those in the largest size class, have a negative or zero growth. Decay and erosion of receptacles is the main reason for this negative growth. As reflected in the phenology of the Fucus distichus population, plant length is positively correlated with reproduction (Pearson's linear correlation coefficient; $r=0.60, p=$ $0.001, \mathrm{n}=26$; see also Ang 1991a), but is negatively correlated with growth rate (Ang 1991b). Reproduction takes place at a time when plants reach their maximum size. Plant growth rate is further slowed because of reproduction.
It thus appears that reproduction in Fucus distichus does not entail a cost in terms of greater mortality and decreased longevity of the fertile plants, but possibly does in terms of growth. Given that the reproductive output is positively correlated with plant size (Ang 1991a), reduced, or negative growth could lead respectively to a slow increase, or decrease, in plant size. This in turn may result in decreased future reproductive output. This close association between reproduction and growth has also been reported in other algae. For example, Dion \& Delepine (1983) reported that autumn-winter recruited fronds of Gigartina stellata (Stackhouse) Batters stopped growing and started to degenerate only if cystocarps occupied frond apices, as occurred in fronds recruited earlier in the season. Fronds recruited later in the year had fewer reproductive structures and apices not occupied by cystocarps continued to grow into the following season without degeneration. On the other hand, Klein (1987) observed that decay of fronds of Dumontia contorta (Gmel.) Rupr. was not always preceded by reproduction. Production of reproductive and non-reproductive biomass was measured by McCourt (1984) in 3 species of Sargassum from Baja California, Mexico. He suggested the existence of an energy trade off between growth and reproduction and between the alternate strategies of sexual reproduction by way of receptacle formation and asexual reproduction by way of investment in the holdfast where new shoots are initiated.

The absence of a survival cost of reproduction, or even the presence of a positive effect of reproduction (as in fertile plants having a lower mortality than nonfertile plants in Fucus distichus), may also be related to the fact that reproductive parts in many algae are photosynthetic. This may indicate a reduced dependence of these reproductive parts on the vegetative part for much of their nutrition. The dependence may also be much more localized, i.e. within the module. This presumably allows the vegetative part to invest its photosynthates to other processes or structures, e.g. production of polyphenols against herbivory (Tugwell $\&$ Branch 1989), that may enhance the survival of the whole plant. In higher plants, it has been suggested that there may be an increased respiration cost of reproduction due to uptake and transport of nutrients required for reproduction, even if reproductive parts of some of these plants are photosynthetic (Bazzaz \& Reekie 1985). Among fucoid algae, movement of photoassimilates from lower parts of the branch towards the apex was demonstrated by Diouris \& Floc'h (1984). Their autoradiographs also showed that translocation was localized within a branch or bifurcation, i.e. assimilates did not move around from one branch to another. There was also no downward movement of assimilates from the apices as well as no upward move- 
ment of assimilates from the holdfast in Fucus serratus. It remains to be demonstrated if formation of a receptacle from the apical branch would increase the rate of assimilate translocation or other physiological rates either for the whole plant or for the specific branch that bears the receptacle. Any increase only in localized translocation or other physiological rates would suggest a lack of interdependence among modules and that reproduction is very much an activity at the modular level. Among larger algae like kelps, the picture is different. It has been shown that reproductive parts of kelps are a sink for resources or photoassimilates generated elsewhere in the plant (see reviews in Schmitz 1981, Buggeln 1983). Reed (1987) reported that vegetative biomass has a great influence on zoospores production in Macrocystis pyrifera (L.) C. Ag. The removal of $75 \%$ of vegetative fronds in this kelp led to a significant reduction in sporophyll production.

The significance of the modular character of algae has been pointed out by Klinger (1988) in her studies on the cost of reproduction in Dictyota binghamiae J. Ag., an isomorphic haplodiplontic alga. She found no evidence of survival cost nor reproductive cost in terms of reduced future reproduction. She argued that the cost of reproduction may be at the modular level, hence may be manifested only in reduced reproductive output, rather than in terms of mortality of the whole plant. Other studies have not distinguished the interactions among modular levels and the results on the cost of reproduction are more equivocal. Bhattacharya (1985) reported that vegetative fronds of Chondrus crispus Stackhouse survived longer than those that bore sori in fall and winter, but both gametophytes and sporophytes have higher or equal survivorship than vegetative thalli in spring and summer. Chapman (1986) found no relationship between sorus area (reproductive output) and subsequent survival in Laminaria longicruris Pyle. Pfister (1990) found no cost of reproduction in terms of resource allocation in plants of Alaria nana Schrader, but those with sporophylls have a $44 \%$ survivorship compared to $68 \%$ in those without.

Fecundity cost of reproduction in Fucus distichus has not been assessed. At the modular level, it is not known if the number of oogonia in each conceptacle is fixed. Each oogonium can produce 8 eggs. The presence of underdeveloped oogonia in spent conceptacles suggests that additional eggs can still develop and be discharged (Ang 1991a), i.e. there can still be future reproductive output. But if the number of oogonia within a conceptacle is fixed, then any reduction in future reproductive output may be related more to reproductive determinism (sensu Bell \& Koufopanou 1986) than to cost of reproduction. It is unlikely that the number of eggs discharged from one conceptacle will be affected by those discharged from the others, or that the number discharged at one time in one conceptacle will affect the number that will be discharged from other conceptacles in the future. Unless there is translocation of limited resources or other growth substances among them, conceptacles are probably physiologically independent from each other. Evidences of translocation in fucoid algae have indicated only apical translocation of photoassimilates from lower parts of the branches (Floc'h \& Penot 1972, Floc'h 1982, Diouris \& Floc'h 1984, Penot et al. 1985 , Diouris 1989). It is not known if there is any localized movement between conceptacles. At the whole plant level, there is no evidence that receptacle formation in one branch would reduce the chances of receptacle formation in other branches. This suggests that reduction in future reproduction is probably minimal. Cost difference between sexes in $F$. distichus cannot be assessed as the plants are monoecious.

The present study and all other studies on algae so far have only been concerned with phenotypic correlations among unmanipulated individuals. Bell \& Koufopanou (1986) emphasized the importance of an experimental approach combined with genetic correlation of fitness components in evaluating the cost of reproduction. It has been shown that mortality in semelparous plants like soybean can be delayed by removal of the flower buds (Leopold 1961). Such an approach, however, could induce stress on the plants. Reekie (1989) manipulated photoperiod to induce or suppress flowering in Plantago spp. This approach can avoid the potential artifact associated with physical injuries of removing flower and seed buds and may be adaptable for use in algae. Fritsch (1945) reported that some fucoids growing in a salt marsh propagate only vegetatively, although some have non-functional female reproductive structures. These are potential materials for genetic analysis and comparison with fully functional individuals. Klinger (1988) argued that the existence of a low cost of reproduction may explain the persistence of a biphasic life history in algae, wherein there are 2 reproductive events, sporogenesis and gametogenesis. If there is a high cost in reproduction, then selection should favour a reduction in the number of reproductive events, as in a diplontic life history. It is interesting to note that Fucus distichus, having a diplontic life history, has also shown a low cost in reproduction. One could argue that a biphasic life history could still be favoured if the benefits of an increase in dispersal events of the products of sporogenesis and gametogenesis outweigh the high cost of maintaining these multiple reproductive events. Further studies using experimental approaches and genetic correlation are needed to elucidate the significance of the cost of reproduction on the evolution of life history strategies in algae. 
Acknowledgements. This study was partially funded by Natural Science and Engineering Research Council of Canada grant no. 5-89872 to R. De Wreede, and by a Sigma Xi grant-in-aid. I thank R. De Wreede for his supervision and advice, Bob Rodger for suggestions on statistical analysis. Critical comments from R. De Wreede, P. G. Harrison, T Klinger, T. Norton, R. Turkington, S. Williams and 3 anonymous reviewers greatly improved earlier drafts of the manuscript. I held an University of British Columbia Graduate Fellowship, an International Centre for Ocean Development Fellowship, an Edith Asthon Memorial Scholarship, and a Kit Malkin Scholarship during the duration of this study. The revision of the manuscript was undertaken during my tenure as a post-doctoral fellow at the Halifax Fisheries Research Laboratory, Fisheries and Oceans Canada.

\section{LITERATURE CITED}

Åberg, P. (1990). Population ecology of Ascophyllum nodosum: demography and reproductive effort in stochastic environments. Ph.D. dissertation, Univ. Göteborg

Abrahamson, W. G., Caswell, H. (1982). On the comparative allocation of biomass, energy, and nutrients in plants. Ecology 63: 982-991

Abrahamson, W. G., Gadgil, M. (1973). Growth form and reproductive effort in goldenrods (Solidago, Compositae). Am. Nat. 107: 651-661

Ang, P. O. Jr (1985). Phenology of Sargassum siliquosum J Ag. and S. paniculatum J. Ag. (Sargassaceae, Phaeophyta) in the reef flat of Balibago, Calatagan, Philippines. Proc. 5th int coral Reef Congr. 5: 51-57

Ang, P. O. Jr (1991a). Natural dynamics of a Fucus distichus (Phaeophyta, Fucales) population: recruitment and reproduction. Mar. Ecol. Prog Ser. 78: 71-85

Ang, P. O. Jr (1991b). Age-and size-dependent growth and mortality in a population of Fucus distichus. Mar. Ecol. Prog. Ser 78: 173-187

Baardseth, E. (1970). Seasonal variation in Ascophyllum nodosum (L.) Le Jol. in the Trondheims Fjord with respect to the absolute live and dry weight and the relative contents of dry matter, ash and fruit bodies. Botanica mar. 13: $13-22$

Bazzaz, F. A., Reekie, E. G. (1985). The meaning and measurement of reproductive effort in plants. In: White, J. (ed.) Studies on plant demography: a festschrift for John L. Harper. Academic Press, London, p. 373-387

Begon, M., Harper, J. L., Townsend, C. R. (1990). Ecology. Individuals, populations and communities. Blackwell Scientific Publ., Boston

Bell, G. (1980). The costs of reproduction and their consequences. Am. Nat. 116:45-76

Bell, G., Koufopanou, V. (1986). The cost of reproduction. Oxford Surv. evol. Biol. 3: 83-131

Bhattacharya, D. (1985) The demography of fronds of Chondrus crispus Stackhouse. J. exp. mar Biol. Ecol. 91: $217-231$

Brinkhuis, B. H. (1985). Growth patterns and rates. In: Littler, M. M., Littler, D. S. (eds.) Handbook of phycological methods. Ecological field methods: macroalgae. Cambridge Univ. Press, New York, p. 461-477

Buggeln, R. G. (1983). Photoassimilate translocation in brown algae. Prog phycol. Res. 2: 283-332

Caswell, H. (1989). Matrix population models. Sinauer Associates, Inc., Sunderland, MA

Chapin, F. S. III (1989). The cost of tundra plant structures: evaluation of concepts and currencies. Am. Nat. 133: 1-19
Chapman, A. R. O. (1986). Age versus stage: an analysis of age and size specific mortality and reproduction in a population of Laminaria longicruris. J. exp. mar. Biol. Ecol. 97: $113-122$

Cousens, R. (1986). Quantitative reproduction and reproductive effort by stands of the brown alga Ascophyllum nodosum (L.) Le Jolis in south-eastern Canada. Estuar. coast. Shelf Sci. 22: 495-507

De Wreede, R. E., Klinger, I (1988). Reproductive strategies in algae. In: Lovett Doust, J., Lovett Doust, L. (eds.) Plant reproductive ecology. Patterns and strategies. Oxford Univ. Press, New York, p. 267-284

Dion, P., Delepine, R. (1983). Experimental ecology of Gigartina stellata (Rhodophyta) at Roscoff, France, using an in situ culture method. Botanica mar. 26: 201-211

Diouris, M. (1989). Long-distance transport of ${ }^{14} \mathrm{C}$-labelled assimilates in the Fucales: nature of translocated substances in Fucus serratus. Phycologia 28: 504-511

Diouris, M., Floc'h, J. Y. (1984). Long-distance transport of ${ }^{14} \mathrm{C}$-labelled assimilates in the Fucales: directionality, pathway and velocity. Mar. Biol. 78: 199-204

Edelstein, T., McLachlan, J. (1975). Autecology of Fucus distichus ssp. distichus (Phaeophyceae: Fucales) in Nova Scotia, Canada. Mar. Biol 30: 305-324

Edyvean, R. G. J., Ford, H. (1984). Population biology of the crustose red alga Lithophyllum incrustans Phil. 2. A comparison of populations from three areas of Britain. Biol. J. Linnean Soc. 23: 353-363

Floc'h, J. Y (1982). Uptake of inorganic ions and their long distance transport in Fucales and Laminariales. In: Srivastava, L. M. (ed.) Synthetic and degradative processes in marine macrophytes. Walter de Gruyter, Berlin, p. $139-166$

Floc'h, J. Y., Penot, M. (1972). Transport du ${ }^{32} \mathrm{P}$ et ${ }^{86} \mathrm{R}$ chez quelques algues brunes: orientation des migrations et voies de conduction. Physiol. Vég. 10: 677-686

Ford, H., Hardy, F. G., Edyvean, R. G. J. (1983). Population biology of the crustose red alga Lithophyllum incrustans Phil. Three populations on the east coast of Britain. Biol. J. Linnean Soc. 19: 211-220

Fritsch, F. E. (1945). The structure and reproduction of algae, Vol. 2. Foreword, Phaeophyceae, Rhodophyceae, Myxophyceae. Cambridge Univ. Press, Cambridge

Goldman, D. A., Willson, M. F. (1986). Sex allocation in functionally hermaphroditic plants: a review and critique. Bot. Rev. 52: 157-194

Harper, J. L. (1977). Population biology of plants. Academic Press, New York

Harper, J. L., Ogden, J. (1970). The reproductive strategy of higher plants. I. The concept of strategy with special reference to Senecio vulgaris L. J. Ecol. 58: 681-698

Kain, J. M. (1975). The biology of Laminaria hyperborea VII Reproduction of the sporophyte. J. mar. biol Ass. U.K. 55 $567-582$

Klein, B. (1987). The phenology of Dumontia contorta (Rhodophyta) studied by following individual plants in situ at Roscoff, Northern Brittany. Botanica mar. 30: 187-194

Kleinbaum, D. G., Kupper, L. L. (1978). Applied regression analysis and other multivariate methods. Duxbury Press, North Scituate, MA

Klinger, $T$ (1984). Allocation to meiospore production in annual and perennial representatives of the genus Laminaria. M.Sc. thesis, Univ. British Columbia, Vancouver

Klinger, T (1988). Maintenance of the biphasıc life history in isomorphic brown algae. Ph.D. dissertation, Univ. California, San Diego 
Knight, M., Parke, M. (1950). A biological study of Fucus vesiculosus L. and F. serratus L. J. mar. biol. Ass. U.K. 26 : 439-514

Lawrence, J. M. (1986). Proximate composition and standing crop of Durvillaea antarctica (Phaeophyta) in the Bay of Morbihan, Kerguelen (South Indian Ocean). Mar. Ecol. Prog. Ser. 33: 1-5

Lawrence, J. M., McClintock, J. B. (1988). Allocation of organic material and energy to the holdfast, stipe, and fronds in Postelsia palmaeformis (Phaeophyta: Laminariales) on the California coast. Mar. Biol. 99: 151-155

Leopold, A. C. (1961). Senescence in plant development. Science 134: 1727-1732

McCourt, R. M. (1984). Seasonal patterns of abundance, distributions, and phenology in relation to growth strategies of three Sargassum species. J. exp. mar. Biol. Ecol. 74: $141-156$

Novaczek, 1. (1984). Development and phenology of Ecklonia radiata at two depths in Goat Island Bay, New Zealand. Mar. Biol. 81: 189-197

Penot, M., Dumay, J., Pellegrini, M. (1985). Contribution à l'étude de la fixation et du transport du ${ }^{14} \mathrm{C}$ chez Cystoseira nodicaulis (Fucales, Cystoseiraceae). Phycologia 24 : 93-102

Pfister, C. A. (1990). Costs of reproduction in plants: analyses of demography and allocation in an intertidal seaweed. Bull. ecol. Soc. Am. 71(2) Suppl.: 284

Reed, D. C. (1987). Factors affecting the production of sporophylls in the giant kelp Macrocystis pyrifera (L.) C. Ag. J. exp. mar. Biol. Ecol. 113: 61-69

Reekie, E. G. (1989). Cost of reproduction in two plant species with contrasting life histories. Bull. ecol. Soc. Am. 70(2) Suppl.: 237-238

Reekie, E. G., Bazzaz, F. A. (1987a). Reproductive effort in

This article was submitted to the editor plants 1. Carbon allocation to reproduction. Am. Nat. 129 $876-896$

Reekie, E. G., Bazzaz, F. A. (1987b). Reproductive effort in plants. 2. Does carbon reflect the allocation of other resources? Am. Nat. 129: 897-906

Reekie, E. G., Bazzaz, F. A. (1987C). Reproductive effort in plants. 3. Effect of reproduction on vegetative activity. Am. Nat. 129: $907-919$

Schiel, D. R. (1985). A short-term demographic study of Cystoseira osmundacea (Fucales: Cystoseiraceae) in central California. J. Phycol. 21: 99-106

Schmitz, K. (1981). Translocation. In: Lobban, C. S., Wynne, M. J. (eds.) The biology of seaweeds. Univ. California Press, Berkeley, p. 534-558

Sokal, R. R., Rohlf, F. J. (1981). Biometry, 2nd edn. W. H. Freeman and Co., New York

Thompson, K., Stewart, A. J. A. (1981). The measurement and meaning of reproductive effort in plants. Am. Nat. 117 $205-211$

Tugwell, S., Branch, G. M. (1989). Differential polyphenolic distribution among tissues in the kelps Ecklonia maxima, Laminaria pallida and Macrocystis angustifolia in relation to plant-defense theory. J. exp. mar. Biol. Ecol. 129: $219-230$

Vernet, P., Harper, J. L. (1980). The costs of sex in seaweeds Biol. J. Linnean Soc. 13: 129-138

Weiner, J (1988). The influence of competition on plant reproduction. In: Lovett Doust, J., Lovett Doust, L. (eds.) Plant reproductive ecology. Patterns and strategies. Oxford Univ. Press, New York, p. 228-245

Wilkinson, L. (1988). SYSTAT: the system for statistics. SYSTAT, Inc., Evanston, IL

Zar, J. H. (1984). Biostatistical analysis, 2nd edn. PrenticeHall, Inc., Englewood Cliffs

Manuscript first received: July 2, 1991

Revised version accepted: October 12, 1992 